\title{
Theoretical Description for an Efficient Rhenium Electrocatalytical Recuperation by Polypyrrole Overoxidation
}

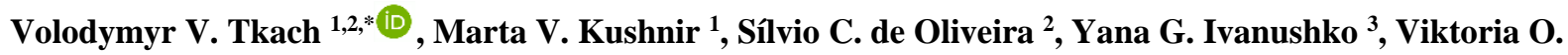 \\ Tkach $^{4}$, Hanna Ya. Mytrofanova ${ }^{4}$, Anatolii O. Zadoia ${ }^{4}$, Petro I. Yagodynets' ${ }^{1}$, Zholt O. Kormosh ${ }^{5}$, Olga \\ V. Luganska' 6

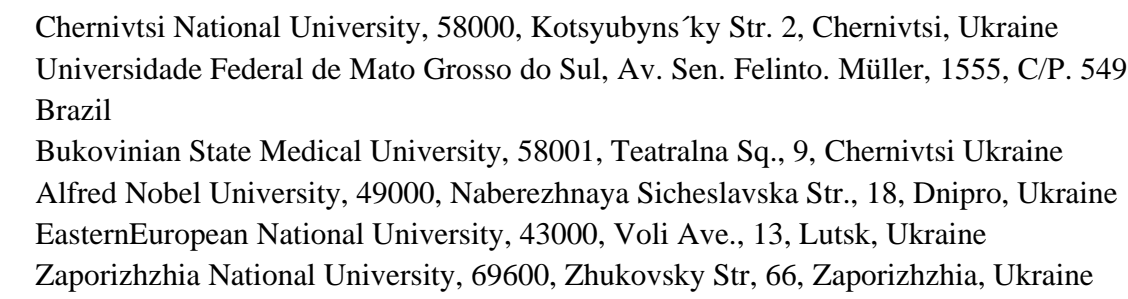

Scopus Author ID 55758299100

Received: 10.10.2020; Revised: 6.01.2021; Accepted: 10.01.2021; Published: 19.01.2021

\begin{abstract}
An interesting process for rhenium recuperation during the polypyrrole overoxidation has been theoretically described. The correspondent mathematical model has been developed and analyzed using linear stability theory and bifurcation analysis. The model's analysis confirms the possibility for the efficient rhenium ion capture by polypyrrole overoxidation, yielding a long-living electrocatalytic material. On the other hand, oscillatory instability is also possible in both stages.
\end{abstract}

Keywords: rhenium; overoxidized polypyrrole; catalytic material; recuperation; electropolymerization; stable steady-state.

(C) 2020 by the authors. This article is an open-access article distributed under the terms and conditions of the Creative Commons Attribution (CC BY) license (https://creativecommons.org/licenses/by/4.0/).

\section{Introduction}

Polypyrrole is one of the most widely used conducting polymers [1-4]. As the pyrrole monomer is cheaper than the carbocyclic analogs and more active than thiophene, it has some advantages compared to their polymers. Therefore, it has a vast and rich gam of uses, beginning with corrosion-protecting coatings and finishing at sensors and biosensors.

One of the severe disadvantages of polypyrrole is that it cannot be used at relatively high potentials due to its irreversible overoxidation [5-6]. It makes breaks the conjugated system, reducing the conductivity seriously. On the other hand, the oxygen-containing functional groups and pyridinic nitrogen appear in its structure. It makes it possible for the overoxidized polymer to form complexes with transition metals [6].

One of these metals is rhenium [7-10]. Discovered in 1924, rhenium is widely used as a high-fusing, anticorrosive and catalytic additive to steels and other metallic alloys. Also, its compounds are used as long-living catalysts [11 - 13]. Rhenium forms many complex compounds in oxidation states from 0 to +7 , including the famous complex ion $\left[\operatorname{Re}_{2} \mathrm{Cl}_{8}\right]^{2-}$, which contains a quadruple bond between two rhenium atoms (Fig. 1): 


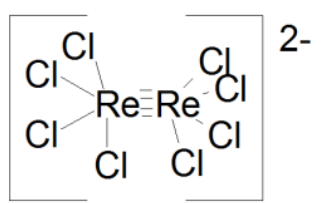

Figure 1. Octochlorodirrhenate ion.

Although rhenium has already obtained its wide use, generally in catalysis, it is a rare metal, which has already been considered dissipated till recent times. Its unique economically efficient mine is on the cratera of Kudryavy (Iodake) volcano, on the island of Iturup, also known as Etorofu, controlled by Russia and claimed on Japan. Therefore, the process of Rhenium recuperation and recyclization is actual [12-16], and the polypyrrole overoxidation with the next complexation of rhenium could give it a good service, as it yields an interesting long-living catalyst.

Nevertheless, both electropolymerization and overoxidation of polypyrrole [17-18] tend to be accompanied by electrochemical instabilities. Besides strong kinetical influences on the process, those instabilities may cause significant changes in the resulting catalytic material morphology, rhenium recuperation efficiency, and electrochemical apparatus.

Therefore, to describe the behavior of the polypyrrole overoxidation in the presence of rhenium-containing waste, resulting in an ecologically and economically efficient rhenium recuperation into another catalytic material, we theoretically analyze the system. By analyzing the correspondent mathematical model, we make conclusions concerning the steady-state stability and electrochemical instabilities in this system. Also, we evaluate the system's behavior by comparing it with similar ones [19-21].

\section{Materials and Methods}

\subsection{System and its modeling.}

The simplified scheme of the rhenium recapture by the overoxidized polypyrrole may be exposed in Fig. 2:

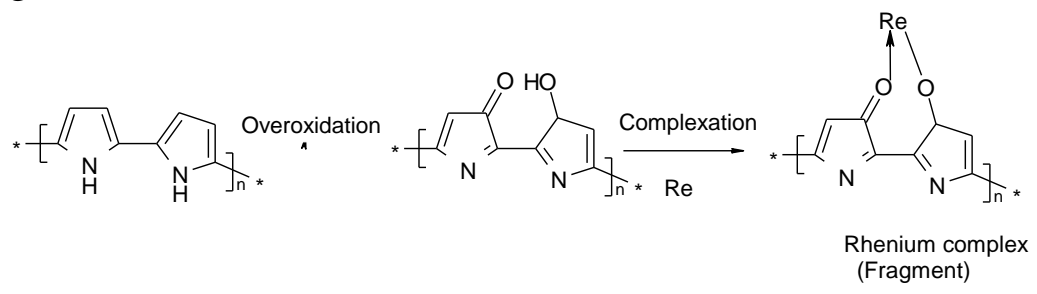

Figure 2. Polypyrrole overoxidation and Rhenium recapture.

In the simplest case, in which the rhenium complex, after its formation, isn't oxidized, we introduce two variables:

$\mathrm{p}$ - non-coordinated overoxidized polypyrrole surface coverage degree;

$r$ - heptavalent rhenium-containing ion concentration in the pre-surface layer.

In order to simplify the modeling, we assume that:

- the background electrolyte is taken in excess so that we can neglect the migration flow and the oxidizing dopant oxidation change;

- the reactor is intensively stirred so that we may neglect the convection flow;

- the pre-surface layer concentration profile is linear, and its thickness is constant, equal to $\delta$. 
It is possible to prove that the differential equations' set describing the system may be described as:

$$
\left\{\begin{array}{c}
\frac{d p}{d t}=\frac{1}{P}\left(v_{0}-v_{c}\right) \\
\frac{d r}{d t}=\frac{2}{\delta}\left(\frac{\Delta}{\delta}\left(r_{0}-r\right)-v_{c}\right)
\end{array}\right.
$$

Herein, $\mathrm{P}$ is the overoxidized polypyrrole maximal surface concentration, $\Delta$ is the diffusion coefficient, $\mathrm{r}_{0}$ is the heptavalent rhenium derivative bulk concentration, and the parameters $\mathrm{v}$ are overoxidation and complexation rates, which may be calculated as:

$$
\begin{gathered}
v_{0}=k_{0}(1-p) \exp \frac{n F \varphi_{0}}{R T} \\
v_{c}=k_{c} p r \exp (-\alpha p r)
\end{gathered}
$$

Herein, the parameters $\mathrm{k}$ are the correspondent reaction rate constants, $\mathrm{n}$ is the number of electrons transferred, $\alpha$ is the parameter, relating the complexation and the surface and double electric layer (DEL) conductivity and ionic force, $\mathrm{F}$ is the Faraday number, $\varphi_{0}$ is the potential slope in DEL, related to the zero-charge potential, $\mathrm{R}$ is the universal gas constant, and $\mathrm{T}$ is the absolute temperature of the solution.

Considering that, in this system, a conducting compound is transferred to a nonconducting during the overoxidation and to another conducting form during the complexation, the surface conductivity will be cyclically changed, which contributes to the oscillatory behavior. Nevertheless, it doesn't impede the efficient, economical, and green process of rhenium recuperation, as shown below.

\section{Results and Discussion}

In order to describe the process of rhenium electrocatalytic recuperation by polypyrrole overoxidation, we analyze the equation-set (1), taking into account the algebraic relations (2 3) using steady-state stability theory. The steady-state Jacobian elements for this set may be exposed as:

$$
\left(\begin{array}{ll}
a_{11} & a_{12} \\
a_{21} & a_{22}
\end{array}\right)
$$

Herein,

$$
\begin{aligned}
& a_{11}=\frac{1}{P}\left(-k_{O} \exp \frac{n F \varphi_{0}}{R T}-j k_{O}(1-p) \exp \frac{n F \varphi_{0}}{R T}-k_{c} r \exp (-\alpha p r)+\alpha k_{c} p r \exp (-\alpha p r)\right) \\
& a_{12}=\frac{1}{P}\left(-k_{c} p \exp (-\alpha p r)+\alpha k_{c} p r \exp (-\alpha p r)\right) \\
& a_{21}=\frac{2}{\delta}\left(-k_{c} r \exp (-\alpha p r)+\alpha k_{c} p r \exp (-\alpha p r)\right) \\
& a_{22}=\frac{2}{\delta}\left(-\frac{\Delta}{\delta}-k_{c} p \exp (-\alpha p r)+\alpha k_{c} p r \exp (-\alpha p r)\right)
\end{aligned}
$$

The principal conditions for the system singular points are exposed in Table 1:

Table 1. The bivariant systems' main singular point requirements.

\begin{tabular}{l|c} 
Steady-state stability & $\operatorname{Tr} \mathrm{J}<0$, Det $\mathrm{J}>0$ \\
\hline Oscillatory instability (Hopf bifurcation) & $\operatorname{Tr} \mathrm{J}=0$, Det $\mathrm{J}>0$ \\
\hline Monotonic instability (saddle-node or static bifurcation) & $\operatorname{Tr} \mathrm{J}<0$, Det $\mathrm{J}=0$
\end{tabular}

Considering the elements (5) and (8), the oscillatory behavior is capable of appearing in this system. The main Hopf bifurcation condition is realized if the main diagonal contains positive elements related to the positive callback.

Two elements, capable of being positive, are part of the main diagonal: 
- $-j k_{O}(1-p) \exp \frac{n F \varphi_{0}}{R T}>0$, if $\mathrm{j}<0$ describing the DEL influences of the overoxidation. As the overoxidized polypyrrole is less conducting, the double electric layer structure suffers rearrangements, leading to the conductivity reduction. It will be responsible for the cyclic change of the electrode current, manifested in the oscillatory behavior;

- $\alpha k_{c} p r \exp (-\alpha p r)$, if $\alpha>0$, describing the DEL rearrangement, caused by the complex formation and conductivity enhancement, contrary to the conductivity decay, mentioned above. The oscillations amplitude will be dependent on the background electrolyte composition, as in [18-19].

However, if the mentioned conditions are not satisfied, steady-state stability will be obtained. In order to avoid the cumbersome expressions, we expose the Jacobian determinant as:

$$
\frac{2}{\delta P}\left|\begin{array}{cc}
-\Omega-\Xi & -\Lambda \\
-\Xi & -\kappa-\Lambda
\end{array}\right|
$$

Mathematically, its condition will be described as:

$$
\left\{\begin{array}{c}
\frac{1}{P}(-\Omega-\Xi)-\frac{2}{\delta}(-\kappa-\Lambda)<0 \\
\frac{2}{\delta P}(\Omega \kappa+\Xi \kappa+\Omega \Lambda)>0
\end{array}\right.
$$

Defining an efficient Rhenium-based catalytical material formation as a result of rhenium recycling. The process will be diffusion-controlled. The condition (8) is easily satisfied, providing a green and economic rhenium recuperation into an efficient catalytic material.

The margin between the steady stable-states and unstable states, shown as an $\mathrm{N}$-shaped part of the voltammogram, will define the monotonic instability. Its condition will be depicted as:

$$
\left\{\begin{array}{c}
\frac{1}{P}(-\Omega-\Xi)-\frac{2}{\delta}(-\kappa-\Lambda)<0 \\
\frac{2}{\delta P}(\Omega \kappa+\Xi \kappa+\Omega \Lambda)=0
\end{array}\right.
$$

This work describes the simplest potentiostat rhenium recapture from heptavalent rhenium-containing wastewater. Real systems with low-valent rhenium compounds and in galvanostatic and potentiodynamic mode will be more dynamic. Their behavior will be shown in our next works.

\section{Conclusions}

From the theoretical evaluation of rhenium recapture by polypyrrole overoxidation, it has been possible to conclude that it is an efficient electro synthetic technique. The resulting material is to be an efficient long-life catalytic material. As for the process, it tends to be diffusion-controlled, providing smooth well-developed material deposition. In its turn, the oscillatory behavior is expected to be probable due to the double electric layer structure changes during both stages. The probability of the oscillatory behavior and the oscillation amplitude will depend on the solution's background electrolyte composition.

\section{Funding}

This research received no external funding. 


\section{Acknowledgments}

This research has no acknowledgment.

\section{Conflicts of Interest}

The authors declare no conflict of interest.

\section{References}

1. Harjo, M.; Zondaka, Z.; Leemets, K.; Järvekülg, M.; Tamm, T.; Kiefer, R. Polypyrrole-coated fiberscaffolds: Concurrent linear actuation and sensing. Journal of Applied Polymer Science 2020, 137, https://doi.org/10.1002/app.48533.

2. Capáková, Z.; Radaszkiewicz, K.A.; Acharya, U.; Truong, T.H.; Pacherník, J.; Bober, P.; Kašpárková, V.; Stejskal, J.; Pfleger, J.; Lehocký, M.; Humpolíček, P. The biocompatibility of polyaniline and polypyrrole 21: Doping with organic phosphonates. Materials Science and Engineering: C 2020, 113, https://doi.org/10.1016/j.msec.2020.110986.

3. Maharjan, B.; Kaliannagounder, V.K.; Jang, S.R.; Awasthi, G.P.; Bhattarai, D.P.; Choukrani, G.; Park, C.H.; Kim, C.S. In-situ polymerized polypyrrole nanoparticles immobilized poly( $\varepsilon$-caprolactone) electrospun conductive scaffolds for bone tissue engineering. Materials Science and Engineering: C 2020, 114, https://doi.org/10.1016/j.msec.2020.111056.

4. Li, J.; He, Y.; Sun, Y.; Zhang, X.; Shi, W.; Ge, D. Synthesis of Polypyrrole/V2O5 Composite Film on the Surface of Magnesium Using a Mild Vapor Phase Polymerization (VPP) Method for Corrosion Resistance. Coatings 2020, 10, https://doi.org/10.3390/coatings10040402.

5. Koseoglu, T.S.; Durgut, A. Development of a Novel Molecularly Imprinted Overoxidized Polypyrrole Electrode for the Determination of Sulfasalazine. Electroanalysis 2020, 32, 2072-2081.

6. Bagheri, A.; Hassani Marand, M. Voltammetric and Potentiometric Determination of Cu2+ Using an Overoxidized Polypyrrole Based Electrochemical Sensor. Russian Journal of Electrochemistry 2020, 56, 453-461, https://doi.org/10.1134/S1023193520060026.

7. Majumder, S.; Borah, B.P.; Bhuyan, J. Rhenium in the core of porphyrin and rhenium bound to the periphery of porphyrin: synthesis and applications. Dalton Trans. 2020, 25, 8419-8432

8. Frei, A.; Amado, M.; Cooper, M.; Blaskovich, M. Light-Activated Rhenium Complexes with Dual Mode of Action Against Bacteria. Chem. Eur. J. 2020, 26, https://doi.org/10.1002/chem.101904689.

9. Capper, M.S.; Packman, H.; Rehkamper, M. Rhenium-Based Complexes and In Vivo Testing: A Brief History. ChemBioChem. 2020, 21.

10. Dobrzanska-Danikewicz, A.D.; Wolany, W. A Rhenium Review - From Discovery to Novel Applications. Arch. Mat. Sci. Eng. 2016, 82, 70-78, https://doi.org/10.5604/01.3001.0009.7106.

11. Haase, A.A.; Bauer, E.D.; Kuhn, F.E.; Crans, D.C. Speciation and Toxicity of Rhenium Saltws, Organometallics and Coordination Complexes. Coord. Chem. Rev., 2019, 394, 135-161, https://doi.org/10.1016/j.ccr.2019.05.012.

12. Bhale, S.; Gore, V.; Tekale, S.; Pawar, R. Synthesis, Characterization and Antimicrobial Activity of Ni(II), $\mathrm{Zn}(\mathrm{II})$ and $\mathrm{Cd}(\mathrm{II})$ Complexes of 3/4-bromo-benzoic acid (Phenyl-pyridine-2-yl-methylene)-Hydrazide Ligand. Lett. Appl. NanoBioSci. 2020, 9, 1529-1537, https://doi.org/10.33263/LIANBS94.15291537.

13. Gavisiddegowds, P.; Kollur, S.P.; Syed, I; Revanasiddappa, H.D. Novel Benzimidazole Derived ImineBased Ligand and its $\mathrm{Co}(\mathrm{III}), \mathrm{Ni}(\mathrm{III}), \mathrm{Cu}(\mathrm{II})$ and $\mathrm{Pt}(\mathrm{II})$ Complexes: Chemical Synthesis, Structure, Antimicrobial, DNA Interaction Studies and Nuclease Activity. Lett. Appl. NanoBioSci. 2020, 9, 1655-1672, https://doi.org/10.33263/LIANBS94.16551672.

14. Kasikov, A.G.; Shchelokova, E.A.; Dvornikova, A.M. Recovery of Rhenium from Sulfuric Acid Solution by TOPO-Impregnated Silica Sorbents. Sep. Sci. https://doi.org/10.1080/01496395.2020.1718709.

15. Kuznetsova, O.G; Levin, A.M.; Sevostyanov, M.A.; Bolshih, A.O. The Improvement of Rhenium Recovery Technology from W-Re Alloys. J. Phys. Conf. Sci. 2018, 1134, https://doi.org/10.1088/17426596/1134/1/012032.

16. Joo, S.-H.; Kim, Y.-U.; Kang, J.-G.; Yoon, H.-S.; Kim, D.-S.; Shin, S.M. Recovery of Molybdenum and Rhenium Using Selective Precipitation Method from Molybdenite Roasting Dust in Alkali Leaching Solution. MATERIALS TRANSACTIONS 2012, 2038-2042, https://doi.org/10.2320/matertrans.M2012209.

17. Das, I.; Goel, N.; Agrawal, N.R.; Gupta, S.K. Growth patterns of dendrimers and electric potential oscillations during electropolymerization of pyrrole using mono-and mixed surfactants. J. Phys. Chem. B 2010, 114, 12888-12896, https://doi.org/10.1021/jp105183q. 
18. Das, I.; Goel, N.; Gupta, S.K.; Agrawal, N.R. Electropolymerization of pyrrole: Dendrimers, nano-sized patterns and oscillations in potential in presence of aromatic and aliphatic surfactants. J. Electroanal. Chem. 2012, 670, 1-10, https://doi.org/10.1016/j.jelechem.2012.01.023.

19. Tkach, V.V.; Kushnir, M.V.; Ivanushko, Y.G.; de Oliviera, S. The Theoretical Description for Neotame Electrochemical Determination, Assisted by Vanadium Oxyhydroxide Composite with a Squarainic Dye. Appl. J. Env. Eng. Sci. 2020, 6, 109-115.

20. Tkach, V.V.; Kushnir, M.V.; Storoshchuk, N.M.; Ivanushko, Y. The Theoretical Description for the Confection of the Novel Thiourea-Based Active Surface for Cathodic Conducting Polymer Deposition. Appl. J. Env. Eng. Sci. 2020, 6, 143-148.

21. Tkach, V.; Kushnir, M.; Ivanushko, Y.; de Oliveira, S.; Reis, L.; Yagodynets', P.; Kormosh, Z. The Theoretical Description for the Electrochemical Synthesis of Squaraine Dye Doped Conducting Polymer. Appl. J. Env. Eng. Sci. 2020, 6, 51-56. 